\title{
A krimpsiekte-like syndrome in small stock poisoned by Ornithogalum toxicarium Archer \& Archer
}

\author{
C J Botha ${ }^{a}$, R A Schultz ${ }^{b}$, J van der Lugt ${ }^{c}$ and C Archer ${ }^{d}$
}

\begin{abstract}
Krimpsiekte (the syndrome associated with chronic cardiac glycoside poisoning) was purportedly induced by Ornithogalum toxicarium in the Karas mountains area of Keetmanshoop, Namibia. This chinkerinchee species was previously linked to a condition known as 'kwylbek' krimpsiekte in small stock in the Beaufort West district of the Western Cape Province, South Africa. In a dosing trial, respiratory distress, tachycardia and sternal recumbency were observed in 2 sheep drenched with fresh plant material. A fluorescence polarisation immunoassay (FPIA) detected the presence of a substance that cross-reacted with digoxin antibodies in some of the plant material collected at Keetmanshoop and Beaufort West. This is the first time that apparent cardiac glycoside poisoning was induced by a southern African chinkerinchee species. The presence of the cardiac glycoside-like substance in $O$. toxicarium requires further chemical verification.
\end{abstract}

Key words: cardiac glycoside poisoning, chinkerinchee, goats, krimpsiekte, Ornithogalum, sheep.

Botha C J, Schultz R A, Van der Lugt J J, Archer C A krimpsiekte-like syndrome in small stock poisoned by Ornithogalum toxicarium Archer \& Archer. Journal of the South African Veterinary Association (2000) 71(1): 6-9 (En.). Department of Pharmacology and Toxicology, Faculty of Veterinary Science, University of Pretoria, Private Bag X04, Onderstepoort, 0110 South Africa.

\section{INTRODUCTION}

During the last few years reports have been received from farmers of large numbers of sheep and goats dying of an unknown plant poisoning in the Keetmanshoop district, Namibia. A small bulbous plant, which sprouted soon after good winter rain $(>20 \mathrm{~mm}$ ) and provided the only greenery available on the barren rangeland, was ingested by small stock. Stiffness, lagging behind the rest of the flock, a tucked-in appearance, weakness, recumbency, neck paresis, torticollis, jerky respiration, groaning, dysphagia and occasional mild to moderate diarrhoea in sheep and goats were reported by the stock owners. When stressed, the animals succumbed more rapidly and high mortality was reported. The farmers referred to the syndrome as krimpsiekte.

'Kwylbek' krimpsiekte or 'natbek'

aDepartment of Pharmacology and Toxicology, Faculty of Veterinary Science, University of Pretoria, Private Bag Xeterinary Science, University of Preto

Toxicology Section, Onderstepoort Veterinary Institute Private Bag X05, Onderstepoort, 0110 South Africa.

'Department of Pathology, Faculty of Veterinary Science, University of Pretoria.

'National Botanical Institute, Private Bag X101, Pretoria 0001 South Africa.

Received: June 1999. Accepted: September 1999*.

*Publication was delayed to permit the description of the new species to be published first. krimpsiekte has also been diagnosed in the Beaufort West district and Merweville region of the Western Cape Province, South Africa (W Crouse and J Pienaar, state veterinarians, Beaufort West and De Aar, pers comm., 1997). The curled leaves of a small bulbous plant emerge soon after rains when Rhigozum obovatum (geelgranaatbos) is in bloom. Small stock, especially Dorper sheep and Angora goats, are usually affected during October and November, but if the first rains are delayed the condition may occur later in the season. The animals are reported to be paretic, show signs of colic and stand with an arched back. Salivation ('kwylbek') is conspicuous. Preliminary dosing trials with plant material obtained from Rhigozum obovatum and the small bulbous plant incriminated the bulbous plant as the cause of toxicity (J Pienaar, state veterinarian, De Aar, pers comm., 1997).

More recently, Bamhare ${ }^{2}$ reported suspected cardiac glycoside intoxication in small stock in the Karas mountains region of southern Namibia. An estimated 2077 sheep and 759 goats had died, presumably of Ornithogalum nanodes Leighton poisoning. Intoxicated small stock had a tucked-in appearance and exhibited signs of star-gazing, torticollis, abdominal breathing, ruminal stasis, muscle trembling, tremors and tired rapidly when mustered. Diarrhoea was only observed on 1 occasion. Necropsy findings were non-specific and included pulmonary oedema and congestion, and congestion of the liver.

Poisoning of livestock with cardiac glycoside-containing plants is collectively the most important plant poisoning in southern Africa ${ }^{11}$. Chemically, 2 major groups of cardiac glycosides, namely the cardenolides and bufadienolides, are recognised. Poisoning by bufadienolidecontaining plants, which surpasses cardenolide-induced poisonings in importance, may be either acute or chronic $^{10,11}$. Tulp poisoning (induced by various Homeria and Moraea species) and slangkop poisoning (caused by various Urginea species) induce only acute toxicity, as these species contain non-cumulative bufadienolides ${ }^{10,11}$. Acute poisoning is characterised by arrhythmia, runs of tachycardia, heart-block, dyspnoea, posterior paresis, bloat and diarrhoea or constipation $^{10,11}$.

Typical krimpsiekte, a chronic form of cardiac glycoside poisoning, manifests as a paretic syndrome predominantly of small stock. It is induced by 3 genera of the Crassulaceae (Cotyledon, Tylecodon and Kalanchoe) which contain neurotoxic bufadienolides ${ }^{3,4,10}$. However, acute poisoning (occasionally referred to as 'opblaas' krimpsiekte) has also been reported $^{7,8,10}$.

As krimpsiekte has previously not been ascribed to any other plant family or genera, the similarity in the toxicity induced by the incriminated plant and reference to the condition as krimpsiekte by the farmers warranted confirmation.

\section{MATERIALS AND METHODS}

\section{Plant material}

Fresh plant material was collected on the farm Schanzen $\left(27^{\circ} \mathrm{S}, 19^{\circ} \mathrm{E} \mathrm{AB}\right)$, Keetmanshoop district, for botanical identification and dosing trials to ascertain the toxicity of the unknown plant. Fresh plant specimens from the farm Middelwater $\left(32^{\circ} 05^{\prime} S, 22^{\circ} 00^{\prime} \mathrm{E}\right)$, Beaufort 
West district were also submitted for botanical identification.

\section{Laboratory trial}

Two South African Mutton Merino sheep were housed in individual pens with concrete floors at the Laboratory Animal Facility of the Division of Toxicology at the Onderstepoort Veterinary Institute. The sheep had free access to water and were fed a ration consisting of milled lucerne hay and a maize-based concentrate. During a 2-week adaptation period, clinical examinations and electrocardiographic (ECG) (Electromed, Medical Distributors) recordings were carried out weekly. To facilitate ECG recordings, the sheep were placed in a crate equipped with a neck clamp and the ECG leads (Lead 2) connected. Both sheep were deprived of feed and water on Day (D) -1 . On D 0 the sheep were weighed and dosed according to this mass. Once dosing commenced the ECG recordings were performed more regularly (i.e. 2-6 times per day). The plant material was blended and dosed to the sheep according to the regimen indicated in Table 1.

On D 1 a necropsy was performed on Sheep 1 and representative tissues were sampled and preserved in $10 \%$ buffered formalin for histological examination. The tissues were routinely processed and stained with haematoxylin and eosin (HE).

A fluorescence polarisation immunoassay (FPIA) (Abbott TDx Analyzer, Abbott Laboratories, Illinois) using the Digoxin II reagent pack (Abbott Laboratories) was performed on extracts of plant material (bulbs and leaves) obtained from

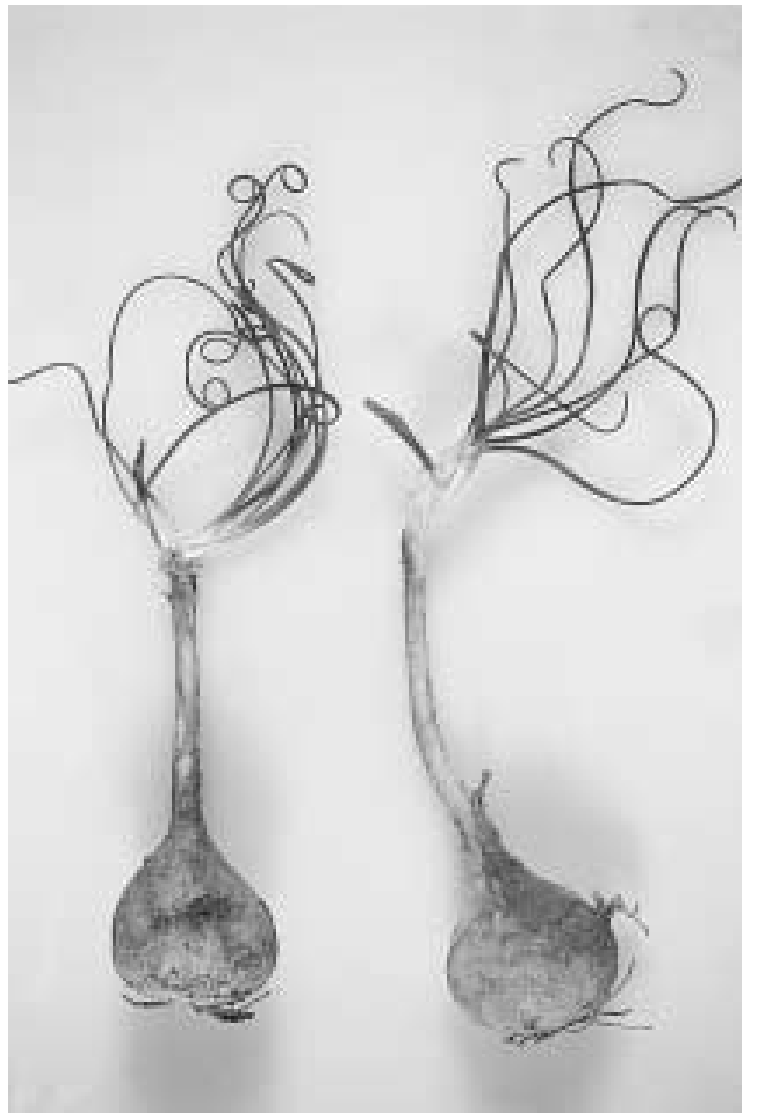

Fig. 1: Ornithogalum toxicarium.

Keetmanshoop and Beaufort West.

\section{RESULTS}

\section{Botanical identification}

Plants collected at both Keetmanshoop and Beaufort West were identified as Ornithogalum toxicarium (Fig. 1). This is a new species of Ornithogalum subgenus Urophyllon (Hyacinthaceae) that has only recently been described ${ }^{1}$. Colloquially, plants of this genus are known as chinkerinchees.

\section{Signs of toxicity}

Clinical signs observed in the sheep are

Table 1: Dosing regimen and clinical signs in sheep following oral dosing of Ornithogalum toxicarium bulbs.

\begin{tabular}{|c|c|c|c|c|c|}
\hline \multirow[t]{2}{*}{ Sheep no. } & \multirow[t]{2}{*}{ Sex } & \multirow{2}{*}{$\begin{array}{c}\text { Body weight } \\
\text { (kg) }\end{array}$} & \multicolumn{2}{|c|}{ Dosing regimen } & \multirow[t]{2}{*}{ Clinical signs $^{a}$} \\
\hline & & & $\begin{array}{c}\text { Dose } \\
\text { (g/kg/day) }\end{array}$ & Days dosed & \\
\hline \multirow[t]{2}{*}{1} & Female & 33.5 & 5 & $0-1$ & Forced, irregular breathing; sinus arrhythmia; runs of tachycardia (D 0). \\
\hline & & & & & $\begin{array}{l}\text { Semi-fluid mucoid diarrhoea; tachypnoea; dyspnoea; grunting; sternal } \\
\text { recumbency; anorexia; ruminal stasis; forced expiration; stridor nasalis. } \\
\text { Terminally an elevated ST-segment, elongated PQ interval and AV-block with } \\
\text { arrhythmias were recorded; died (D 1). }\end{array}$ \\
\hline \multirow[t]{6}{*}{$2^{b}$} & Female & 56.3 & 5 & 0 & Panting (D 0). \\
\hline & & & & & $\begin{array}{l}\text { Shallow, rapid respiration; depressed habitus; moderate gassy bloat; ruminal } \\
\text { stasis; sternal recumbency; reluctance to stand, head hanging low, anorexia (D 1). } \\
\text { Tachycardia; expiratory grunting, abdominal breathing, tachypnoea and } \\
\text { stridor nasalis (= dyspnoea); groaning; anorexia; ruminal stasis (D 2). }\end{array}$ \\
\hline & & & & & Forced respiratory effort; double expiratory movements; groaning (D 3). \\
\hline & & & & & $\begin{array}{l}\text { Frequent recumbency (= paresis); shallow irregular breathing; forced } \\
\text { expiration; grinding of teeth; groaning; lethargic; weak; coughing bouts (D 4-5). }\end{array}$ \\
\hline & & & & & Shallow, irregular breathing (D 6-7). \\
\hline & & & & & Nothing unusual (D 8-11). \\
\hline
\end{tabular}

${ }^{a}$ Clinical signs listed in order of appearance.

${ }^{\mathrm{b}}$ Sheep was treated by dosing $2 \mathrm{~g} / \mathrm{kg}$ activated charcoal (D 1). In addition to activated charcoal, $2.0-2.5 \mathrm{l}$ fresh rumen fluid and ruminotoric (Na-propionate and molasses products (Rumix, Logos Agvet)) were administered on D 2, 5 and 7. Procaine penicillin and benzathine benzyl penicillin (Duplocillin, Intervet SA) were administered intramuscularly on $\mathrm{D} 7$. 
summarised in Table 1 . The respiration of Sheep 1 was severely compromised on D 1. Terminally an atrioventricular block and dissociation were detected.

Sheep 2 exhibited open-mouth breathing, with an extended head and neck, following the stress of dosing with activated charcoal on D1. The most prominent clinical signs on D 2 were forced abdominal breathing, groaning, tachycardia and sternal recumbency. On D 3, although still very weak, the sheep became ambulatory, had a slightly improved appetite and weak ruminal movements returned. By D 11 the animal was fully recovered.

\section{Pathology}

Necropsy examination of Sheep 1 revealed mild, multifocal pulmonary emphysema and atelectasis; mild congestion of the rumen mucosa near the rumenoreticular opening and mild oedema of the abomasal folds; mild oedema and multiple petechial haemorrhages in the mucosa of the anterior $1.5 \mathrm{~m}$ of the small intestine and semi-fluid faecal material. Histological lesions comprised degeneration of scattered myocardial fibres; acute interstitial pneumonia and mild brain oedema.

\section{Fluorescence polarisation immunoassay}

The assay revealed cross-reactivity with digoxin antibodies in half of the plant parts assayed, thus indicating the possible presence of a cardiac glycoside or a cardiac glycoside-like substance, which could be involved in the intoxication (Table 2).

\section{DISCUSSION}

Ornithogalum toxicarium induced an atypical poisoning in small stock referred to as krimpsiekte or 'kwylbek' krimpsiekte. In South Africa there are several highly toxic Ornithogalum species of which O. thyrsoides, O. conicum, O. saundersiae, O. prasinum and O. ornithogaloides are economically important $t^{10,11}$. These species frequently cause severe, persistent diarrhoea in livestock. In O. nanodes poisoning only occasional mild to moderate diarrhoea was reported ${ }^{2}$. Diarrhoea is also not a feature of Crassulaceaeinduced krimpsiekte ${ }^{3,4,9,10}$. The only previously known neurological effect to be caused by the toxic Ornithogalum species is blindness in cattle $\mathrm{e}^{10,11}$.

The clinical signs observed during the laboratory trial are consistent with acute cardiac glycoside intoxication (i.e. dyspnoea, tachycardia, AV-dissociation, ruminal stasis and mucoid diarrhoea) ${ }^{10,11}$ Similarities with experimentally induced krimpsiekte, such as irregular, shallow
Table 2: Cross-reactivity of Ornithogalum toxicarium plant material with digoxin antibodies utilising the fluorescence polarisation immunoassay (FPIA).

\begin{tabular}{lccc}
\hline Source & Date assayed & $\begin{array}{c}\text { Leaves } \\
\text { (measured digoxin } \\
\text { concentration, nmol/ } \ell)\end{array}$ & $\begin{array}{c}\text { Bulbs } \\
\text { (measured digoxin } \\
\text { concentration, nmol/ } \ell \text { ) }\end{array}$ \\
\hline Schanzen, Keetmanshoop & $8 / 10 / 1996$ & $\mathbf{9 8}^{\mathrm{a}}$ & $22^{\mathrm{b}}$ \\
Schanzen, Keetmanshoop & $25 / 11 / 1996$ & $33^{\mathrm{b}}$ & $23^{\mathrm{b}}$ \\
Schanzen, Keetmanshoop & $15 / 10 / 1998$ & $\mathbf{6 8}^{\mathrm{a}}$ & $48^{\mathrm{b}}$ \\
Middelwater, Beaufort West & $25 / 11 / 1996$ & $\mathbf{1 7 6}^{\mathrm{a}}$ & $\mathbf{3 8 0}^{\mathrm{b}}$ \\
\hline
\end{tabular}

${ }^{\mathrm{a}}$ Dried plant material.

${ }^{\mathrm{b}}$ Fresh plant material.

Figures in boldface: interpreted as a positive assay.

breathing, tachypnoea, recumbency, paresis and standing with head hanging low, were also noticed ${ }^{3,4}$. The severe respiratory distress, grunting, groaning and ruminal stasis observed in the sheep during the current dosing trial were consistent with the clinical signs observed during the dosing trial conducted by Bamhare $^{2}$.

The necropsy performed on Sheep 1 revealed mild oedema and multiple, diffuse petechiae in the mucosa of the proximal $1.5 \mathrm{~m}$ of the small intestine. The proximal small intestinal mucosa of ruminants that have died of cardiac glycoside poisoning often shows a diffuse or patchy congestion. One of the sheep dosed with $O$. nanodes plant material also exhibited congestion and haemorrhages of the duodenum and upper third of the small intestine ${ }^{2}$.

In 'kwylbek' krimpsiekte salivation is conspicuous. Excessive salivation has also been reported with krimpsiekte and was ascribed to clonic spasms of the muscles of mastication and deglutition. Half-chewed balls of hay sometimes occluded the pharyngeal passage ${ }^{7}$.

The FPIA has been developed to monitor human patients on digoxin therapy (Abbott Laboratories). Although the assay uses digoxin antibodies, cross-reactivity is sufficient to detect exposure of stock to certain bufadienolide-containing plants (R A Schultz, unpubl. data). It has also been used to detect cardiac glycosides in plant material and to confirm a history suggestive of ingestion of cardiac glycosides in humans ${ }^{5}$. The positive assay in some of the O. toxicarium plant parts suggests the presence of a cardiac glycoside in this Ornithogalum species.

Five cardenolides have previously been isolated from the seeds of O. magnum ${ }^{12}$ and 16 cardenolides have been isolated from the bulbs and leaves of O. umbellatum $^{6}$. Prasinosides A, B, C, D, E and F have been isolated from $O$. prasinum ( $R$ Vleggaar, University of Pretoria, pers. comm., 1999) and prasinoside $\mathrm{G}$ has been isolated from $O$. thyrsoides ${ }^{17}$. These prasinosides share a common steroidal aglycone (a $3 \beta, 16 \beta, 17 \alpha$ - trihydroxycholest-5-en-22-one) $)^{17}$, but are not cardiac glycosides. Several cholestane glycosides have also been isolated from $O$. saundersia $^{9,13-16}$. It has been demonstrated that these cholestane glycosides have cytostatic efficacy against human leukaemic cell lines and an inhibitory activity on cyclic-AMP phosphodiesterase ${ }^{9,14-16}$.

The toxicity of the cholestane or cholestene glycosides in ruminants has not yet been evaluated, but isolation of cardiac glycosides from $O$. toxicarium could explain the krimpsiekte syndrome. In a preliminary investigation a toxic substance was isolated, guided by guinea-pig bioassay, but nuclear magnetic resonance (NMR) analysis showed that it was not a cardiac glycoside. A low yield and impurities prevented specific identification of the compound, which could have been a cholestane glycoside (M Bode, Toxicology Division, Onderstepoort Veterinary Institute, pers. comm., 1999).

The identification of this species as $O$. nanodes as reported by Bamhare ${ }^{2}$ is probably incorrect, as it can easily be confused with $O$. toxicarium. The 2 species are superficially similar in having longnecked bulbs and filiform leaves, but they can be placed in different subgenera on account of their floral morphology. The differences between $O$. nanodes and $O$. toxicarium are summarised in Table 3. Easily recognisable distinguishing characteristics of $O$. toxicarium are the absence of bristles on the neck of the bulb and the more robust inflorescence compared to $O$. nanodes. Ornithogalum toxicarium is probably related to $O$. tenuifolium. corded in the following provinces and districts of South Africa: Northern Cape: Hay and Herbert districts; Western Cape: Murraysburg and Beaufort West districts and Eastern Cape: Middelburg district.
Ornithogalum toxicarium has been re- 


\begin{tabular}{lll}
\hline & O. nanodes ${ }^{\mathrm{a}, \mathrm{b}}$ & O. toxicarium \\
\hline Bulb tunics & Hard and leathery & Soft and membranous \\
Bulb neck & Not gamophyllous, without horizontal markings & Gamophyllous, without horizontal markings \\
Old leaf bases & Persisting as a tuft on top of bulb neck & Early deciduous from top of bulb neck \\
Leaf number & Many & $4-10$ \\
Inflorescence shape & Raceme & Dense rounded head \\
Total inflorescence height & Up to $150 \mathrm{~mm}$ & Up to $25 \mathrm{~mm}$ \\
Shape of floral bract apex & Aristate & Obtuse \\
Flower shape & Crateriform to stellate & Campanulate \\
Pedicel length & $15-30 \mathrm{~mm}$ & $1.5-2.2 \mathrm{~mm}$ \\
Fruit length & $7 \mathrm{~mm}$ & $10-15 \mathrm{~mm}$ \\
Seed description & Comma-shaped, not winged & Oval, broadly winged \\
Seed dimensions & $0.5 \mathrm{~mm}$ long & $8 \times 5-6 \mathrm{~mm}$ \\
\hline
\end{tabular}

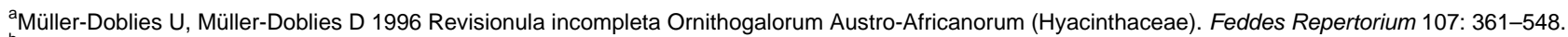

bobermeyer A A 1978 Ornithogalum: a revision of the southern African species. Bothalia 12: 323-376.

Veterinary practitioners in these areas should be aware of this plant intoxication.

\section{ACKNOWLEDGEMENTS}

We thank Prof T S Kellerman (Toxicology Division, Onderstepoort Veterinary Institute) for valuable advice and Drs W Crouse and J Pienaar (State Veterinarians, Beaufort West and De Aar, respectively) for submitting samples of the incriminated plant and sharing their experiences. Messrs Smith and Louwrens are thanked for notifying us of the poisoning and supplying plant material for identification and dosing trials. The experimental work was approved by the Ethic Committee of OVI and the Faculty of Veterinary Science, University of Pretoria

\section{REFERENCES}

1. Archer C, Archer R H 1999 A new species of Ornithogalum subgenus Urophyllon (Hyacinthaceae) from central South Africa and southern Namibia. South African Journal of Botany 65: 431-433

2. Bamhare C 1998 Suspected cardiac glycoside intoxication in sheep and goats in Namibia due to Ornithogalum nanodes (Leighton). Onderstepoort Journal of Veterinary Research 65: 25-30

3. Botha C J, Kellerman T S, Schultz R A, Erasmus G L, Vleggaar R, Retief E 1998 Krimpsiekte in a sheep following a single dose of Tylecodon ventricosus (Burm. f.) Toelken and the isolation of tyledoside D from this plant species. Onderstepoort Journal of Veterinary Research 65: 17-23

4. Botha C J , Van der Lugt J J, Erasmus G L, Kellerman T S, Schultz R A, Vleggaar R 1997 Krimpsiekte, associated with thalamic lesions, induced by the neurotoxic cardiac glycoside, cotyledoside, isolated from Tylecodon wallichii (Harv.) Toelken subsp. wallichii. Onderstepoort Journal of Veterinary Research 64: 189-194

5. Cheung K, Hinds J A, Duffy P 1989 Detection of poisoning by plant-origin cardiac glycosides with the Abbott TDx Analyzer. Clinical Chemistry 35: 295-297

6. Ferth R and Kopp B 1992 Cardenolides from Ornithogalum umbellatum L. Pharmazie 47: 626-629

7. Henning M W 1926 Krimpsiekte. 11th and 12th Reports of the Director of Veterinary Education and Research Part I: 331-365

8. Henning M W 1932 Animal diseases in South Africa, Vol II. South African Agricultural Series Vol XII. Central News Agency, Johannesburg

9. Hirano T, Oka K, Mimaki Y, Kuroda M, Sashida Y 1996 Potent growth inhibitory activity of a novel Ornithogalum cholestane glycoside on human cells: induction of apoptosis in promyelocytic leukemia HL-60 cells. Life Sciences 58: 789-799

10. Kellerman T S, Coetzer J A W, Naudé T W 1988 Plant poisonings and mycotoxicoses of livestock in southern Africa (1st edn). Oxford University Press, Cape Town
11. Kellerman T S, Naudé T W, Fourie N 1996 The distribution, diagnosis and estimated economic impact of plant poisonings and mycotoxicoses in South Africa. Onderstepoort Journal of Veterinary Research 63: 65-90

12. Komissarenko N F 1974 Cardenolides of the seeds of Ornithogalum magnum. Chemistry of natural compounds. Consultants Bureau 8: 395-396

13. Kubo S, Mimaki Y, Sashida Y, Nikaido T, Ohmoto T 1992 New polyhydroxylated cholestane glycosides from the bulbs of Ornithogalum saundersiae. Chemical and Pharmaceutical Bulletin 40: 2469-2471

14. Kuroda M, Mimaki Y, Sashida Y, Hirano T, Oka K, Dobashi A 1995 A novel 16,23epoxy-5 $\beta$-cholestane glycoside with potent inhibitory activity on proliferation of human peripheral blood lymphocytes from Ornithogalum saundersiae bulbs. Chemical and Pharmaceutical Bulletin 43: 1257-1259

15. Mimaki $Y$, Kuroda M, Kameyama A, Sashida Y, Hirano T, Oka K, Koike K, Nikaido T 1996 A new cytotoxic cholestane bisdesmoside from Ornithogalum saundersiae bulbs. Bioscience, Biotechnology and Biochemistry 60: 1049-1050

16. Mimaki Y, Kuroda M, Sashida Y, Hirano T, Oka K, Dobashi A 1996 Three novel rearranged cholestane glycosides from Ornithogalum saundersiae bulbs and their cytostatic activities on leukemia HL-60 and MOLT-4 cells. Tetrahedron Letters 37: 1245-1248

17. Van der Westhuizen D 1996 Structural studies on the toxic principle of Ornithogalum thyrsoides. MSc thesis, University of Pretoria 